\title{
Elimination of shrimp endogenous peroxidase background in immunodot blot assays to detect white spot syndrome virus (WSSV)
}

\author{
Wen-Bin Zhan ${ }^{1, *}$, Jing Chen ${ }^{1}$, Zhi-Dong Zhang ${ }^{1}$, Li Zhou ${ }^{1}$, Hideo Fukuda ${ }^{2}$ \\ ${ }^{1}$ Laboratory of Pathology and Immunology of Aquatic Animals, LMMEC, Ocean University of China, Qingdao 266003, China \\ ${ }^{2}$ Fish Pathology Laboratory, Tokyo University of Fisheries, Tokyo 108-8477, Japan
}

\begin{abstract}
False positive results were obtained in immunodot blot assays to detect white spot syndrome virus when horseradish peroxidase-conjugated sheep anti-mouse immunoglobin (Ig) serum was used as a secondary antibody with 3-3'diaminobenzine tetrahydrochloride dihydrate as the detection substrate. The cause was considered to be a reaction of shrimp endogenous peroxidase (POD) with the substrate. In experiments designed to inhibit POD activity, 9 different reagents were used at different concentrations and for different treatment times. EDTA, sodium azide, HEPES-Na, $\mathrm{NaHSO}_{3}, \mathrm{H}_{2} \mathrm{O}_{2}$ and phenylthiourea (PTU) were able to inhibit POD activity by $44,60,64,67,79$, and $90 \%$, respectively. Phenylmethylsulfonyl fluoride did not inhibit POD, and neither periodic acid nor $\mathrm{H}_{2} \mathrm{O}_{2}$ in methanol were appropriate due to the formation of flocculant precipitates when added to shrimp extracts. It was concluded that of the treatments tested, $10 \mathrm{mM}$ PTU for $2 \mathrm{~h}$ yielded optimal inhibition and that such pretreatment of samples eliminates false positive results in immunodot blot assays.
\end{abstract}

KEY WORDS: Shrimp $\cdot$ Peroxidase $\cdot \mathrm{WSSV} \cdot$ Immunodot blot

Resale or republication not permitted without written consent of the publisher

White spot syndrome virus (WSSV) has caused serious disease in shrimp aquaculture since 1993 (Lo et al. 1996, Kanchanaphum et al. 1998). Despite a huge research effort since then, there still remains a need for rapid, specific, accurate and simple detection methods for WSSV. Shrimp farmers require diagnostic results in the shortest possible time in order to implement preventive or control measures. Antibody-based assays such as immunodot blot assays (Lu et al. 1996, Lightner 1999) satisfy these requirements. However, false positive results were obtained when we used monoclonal antibodies (MAbs) against WSSV in an immunodot blot assay with sheep anti-mouse immunoglobin (Ig) serum conjugated to horseradish peroxidase (HRP) as the secondary antibody and 3-3'-diaminobenzine tetra- hydrochloride dihydrate (DAB) as the detection substrate. Indeed, this problem has been noted previously (Poulos et al. 1994, Lightner 1999).

There are 3 factors that could cause false positive results in immunodot blot assays: (1) low specificity or non-specificity of the primary antibody, (2) inadequate washing following incubation of the primary antibody and secondary antibody, and (3) reaction of endogenous shrimp enzymes with the substrate. The specificity of our MAb against WSSV has been verified previously (Zhan et al. 1999), and extensive washing with phosphate-buffered saline containing $0.05 \%$ Tween 20 (PBS-T) in our assays has not solved the problem. Thus, it is likely that the false positive results arose from an endogenous shrimp peroxidase (POD) with an enzymatic activity similar to the HRP conjugated with our secondary antibody. This report describes experiments carried out to eliminate false positive results that may arise from endogenous POD in immunodot blot assays.

Materials and methods. Collection of shrimp and preparation of samples were as follows:

Preparation of samples: Moribund shrimp (Penaeus japonicus, mean weight $6.1 \mathrm{~g}$ ) with evident cuticular white spots on the carapace were collected from shrimp farms in Shandong Province (PR China). Healthy shrimp (P. japonicus, mean weight $8.5 \mathrm{~g}$ ) with no characteristic WSSV lesions were collected from a shrimp farm in Hebei Province (PR China), where no viral disease had been observed. Gills of moribund or healthy shrimp were homogenized in PBS ( $\mathrm{KCl} 0.2 \mathrm{~g}, \mathrm{NaCl} 8.0 \mathrm{~g}, \mathrm{KH}_{2} \mathrm{PO}_{4}$ $0.2 \mathrm{~g}, \mathrm{Na}_{2} \mathrm{HPO}_{4} 12 \mathrm{H}_{2} \mathrm{O} 2.9 \mathrm{~g}$, distilled water $1000 \mathrm{ml}, \mathrm{pH}$ $7.4)$ for $20 \mathrm{~min}$ on ice at a ratio of $20 \%(\mathrm{w}: \mathrm{v})$ and then centrifuged at $3000 \times g$ for $15 \mathrm{~min}$ at $4^{\circ} \mathrm{C}$. The supernatant fluids were collected and stored at $-80^{\circ} \mathrm{C}$.

Inhibition of shrimp POD activity: Supernatant solution from healthy shrimp homogenates $(25 \mu \mathrm{l})$ was 
mixed with $25 \mu$ l of each test reagent solution in a 96-well microplate. The 9 reagents tested were EDTA $(0.01,0.1$, and $0.5 \mathrm{M})$, sodium azide, $\mathrm{NaN}_{3}(0.01$, $0.1,1 \mathrm{M})$, HEPES-Na $(0.01,0.1,1 \mathrm{M}), \mathrm{NaHSO}_{3}(0.01$, $0.1,1 \mathrm{M}), \mathrm{H}_{2} \mathrm{O}_{2}(0.1,1,10 \%)$, phenylthiourea, PTU $(0.1$, $1,10 \mathrm{mM})$, phenylmethylsulfonyl fluoride, $\operatorname{PMSF}(1,10$, $100 \mathrm{mM}), \mathrm{H}_{2} \mathrm{O}_{2}$ in methanol $(0.1,1,10 \%)$, and periodic acid $(0.01,0.1,1 \mathrm{M})$. Shrimp extracts were incubated with each test reagent and concentration for $0.5,1$, and $2 \mathrm{~h}$. Then $100 \mu \mathrm{l}$ o-phenylenediamine (OPD, $0.4 \mathrm{mg}$ $\mathrm{ml}^{-1}$ ) substrate was added to each well and allowed to react for $10 \mathrm{~min}$ before color development was stopped by addition of $50 \mu \mathrm{l} 2 \mathrm{M} \mathrm{H}_{2} \mathrm{SO}_{4}$. The absorbance was then measured at $490 \mathrm{~nm}$ using a microtiter platereader. Supernatant solution from healthy shrimp homogenates $(25 \mu \mathrm{l})$ in $25 \mu \mathrm{l}$ PBS was used as the negative control. This experiment was repeated 3 times.

Immunodot blot: Supernatant solutions from moribund, WSSV-infected shrimp and healthy shrimp were pretreated with $10 \mathrm{mM}$ PTU $(1: 1, \mathrm{v}: \mathrm{v})$ to inhibit POD activity and were then diluted with PBS (1:1, v:v) as controls. Pretreated and diluted supernatant solutions ( $2 \mu \mathrm{l}$ each) were spotted onto nitrocellulose (NC) membranes in triplicate and air-dried. The NC membranes were blocked with $10 \%$ bovine albumin for $30 \mathrm{~min}$ at $37^{\circ} \mathrm{C}$ and then washed with PBS-T. Next, they were incubated in the primary antibodies (mixture of 6 antiWSSV MAb) for $1 \mathrm{~h}$ at $37^{\circ} \mathrm{C}$ and washed 3 times with PBS-T. MAb-binding was detected using sheep antimouse Ig serum conjugated with HRP (diluted 1:200) for $1 \mathrm{~h}$ at $37^{\circ} \mathrm{C}$ and washed 3 times as above. The positive reactions were visualized using DAB $\left(0.5 \mathrm{mg} \mathrm{ml}^{-1}\right)$ substrate for $5 \mathrm{~min}$.

Results. The results of the POD inhibition experiments are given in Figs. 1 \& 3, those of the immunodot blot assay in Fig. 4.

Inhibition of shrimp POD activity: POD inhibition increased as the concentration of the various reagents tested increased. With respect to pretreatment time, the inhibitors fell into 2 general groups. One group demonstrated increasing inhibition with increasing time, while the other demonstrated little change in degree of inhibition with increasing time. EDTA (Fig. 1) exemplified reagents in the first group, with $0.01 \mathrm{M}$ for up to $2 \mathrm{~h}$ demonstrating very little inhibition. However, increasing the inhibitor concentration or treatment time increased inhibition to a maximum of $44 \%$ at $0.5 \mathrm{M}$ EDTA for $2 \mathrm{~h}$ (Fig. 1). $\mathrm{NaN}_{3}$ (Fig. 2) exemplified reagents in the second group, in that irrespective of inhibitor concentration there was very little increase in inhibition after $0.5 \mathrm{~h}$ incubation. Inhibition of POD was greater than that for EDTA, with inhibition increasing to $60 \%$ for $1 \mathrm{M}$ at $2 \mathrm{~h}$ exposure. For HEPES$\mathrm{Na}$, the inhibition pattern was similar to that for $\mathrm{NaN}_{3}$, with highest inhibition of $64 \%$ at $1 \mathrm{M}$ for $2 \mathrm{~h}$. The inhi- bition pattern for $\mathrm{NaHSO}_{3}$ was similar to that for EDTA, but with $67 \%$ inhibition at $1 \mathrm{M}$ for $2 \mathrm{~h}$. The pattern for $\mathrm{H}_{2} \mathrm{O}_{2}$ was similar to that of $\mathrm{NaHSO}_{3}$, but with higher $(79 \%)$ inhibition at a concentration of $10 \%$ for $2 \mathrm{~h}$.

The most effective inhibitor of POD activity was PTU (Fig. 3), with an inhibition pattern similar to that of $\mathrm{NaN}_{3}$ and providing $90 \%$ inhibition at $10 \mathrm{mM}$ PTU for $2 \mathrm{~h}$.

PMSF had no inhibitory effect on POD activity at the concentrations and exposure times tested. When the supernatant solutions were treated with periodic acid and $\mathrm{H}_{2} \mathrm{O}_{2}$ in methanol, a white flocculant precipitate formed, eliminating them for use with the microplate reader.

Immunodot blot: The result of an immunodot blot assay is shown in Fig. 4. The reaction with untreated moribund shrimp supernatant fluid diluted 1:1 in PBS (Fig. 4, Row 1) was the strongest because it combined

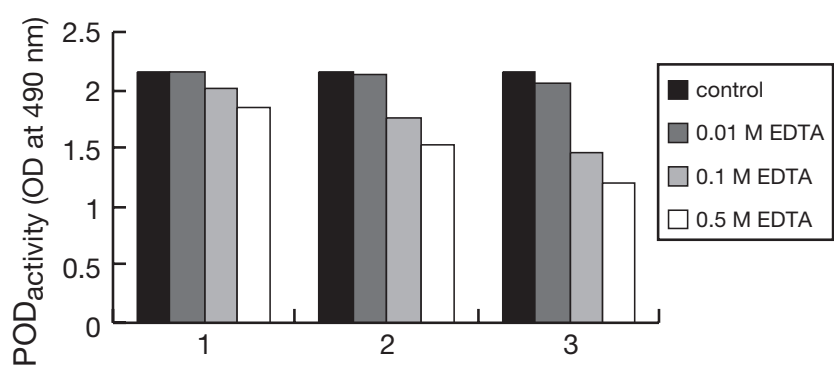

Fig. 1. Effects of EDTA on shrimp endogenous peroxidase (POD) activity. 1,2,3: treated for $0.5,1$ and $2 \mathrm{~h}$, respectively

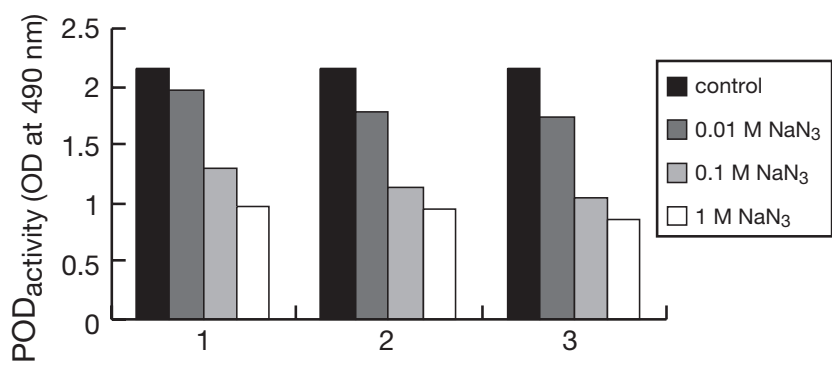

Fig. 2. Effects of $\mathrm{NaN}_{3}$ on shrimp POD activity. 1,2,3: treated for $0.5,1$ and $2 \mathrm{~h}$, respectively

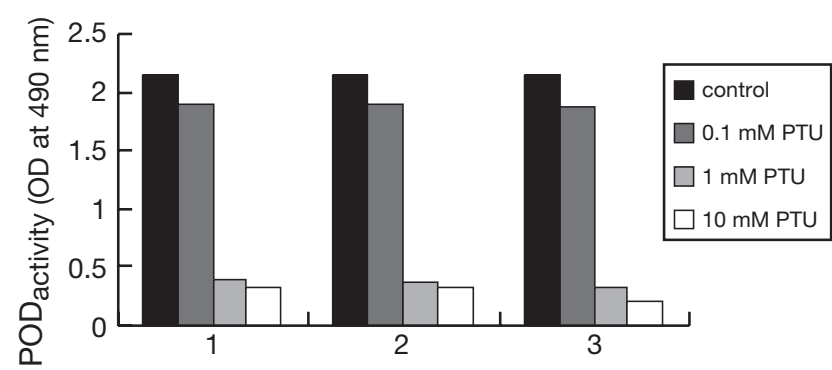

Fig. 3. Effects of phenylthiourea (PTU) on shrimp POD activity. $1,2,3$ : treated for $0.5,1$ and $2 \mathrm{~h}$, respectively 


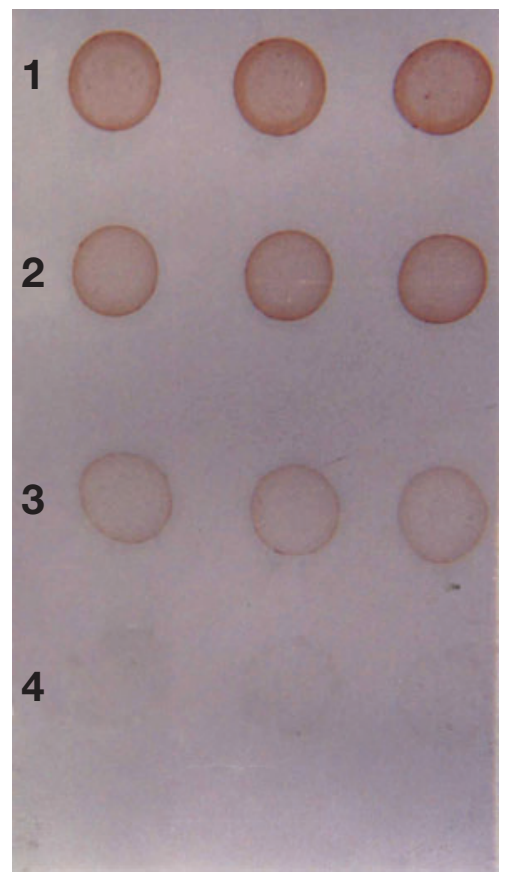

Fig. 4. Color development in the immunodot blot assay (repeated 3 times). 1: Moribund shrimp supernatant solution diluted 1:1 in phosphate-buffered saline (PBS); 2: moribund shrimp supernatant solution pretreated with $10 \mathrm{mM} \mathrm{PTU;} \mathrm{3:} \mathrm{healthy}$ shrimp supernatant solution diluted 1:1 in $\mathrm{PBS}_{;} 4$ : healthy shrimp supernatant solution pretreated with $10 \mathrm{mM}$ PTU

effects of shrimp endogenous POD and exogenous HRP with DAB. Pretreatment of the supernatant with $10 \mathrm{mM}$ PTU (Fig. 4, Row 2) resulted in a lighter color due to the inhibition of endogenous POD by PTU. Healthy shrimp supernatant diluted 1:1 in PBS yielded a false positive background reaction due to endogenous POD (Fig. 4, Row 3) but this was removed by pretreatment with $10 \mathrm{mM}$ PTU (Fig. 4, Row 4).

Discussion. Among the reagents tested in this study, $\mathrm{NaN}_{3}$ and $\mathrm{H}_{2} \mathrm{O}_{2}$ have previously been reported to almost completely inhibit endogenous enzyme activity in marine mussels (Coles \& Pipe 1994). With the shrimp extracts used here, these compounds were not very effective. PMSF has been reported to markedly inhibit phenoloxidase activity of shrimp (Kondo et al. 1992), but it did not inhibit POD activity in the shrimp extracts tested in this study. Although periodic acid and $\mathrm{H}_{2} \mathrm{O}_{2}$ in methanol have been successfully employed for inhibition of endogenous POD activity in immunocytochemical methods (Xu 1997), inhibitory effects could not be

Editorial responsibility: Timothy Flegel, Bangkok, Thailand evaluated here due to the formation of precipitates that interfered with microtiter plate-reader measurements. In summary, PTU was the most effective of all the reagents tested for inhibition of endogenous POD activity without interference in the MAb assay.

Although it could be argued that false positive results could be avoided by including a normal control for background endogenous POD activity, it is possible that some specimens, lightly infected with WSSV, would be graded as background negatives. However, elimination of the background color with PTU would facilitate interpretation of the immunoblot assay. It is also likely that PTU could be applied to eliminate endogenous background activity in other enzyme immunoassays with shrimp, including enzyme-linked immunosorbent assays and immunohistochemical assays where the HRP system is used for detection.

Acknowledgements. This work was supported by grants from NSFC 39870110, National 863 Project, Major State Research Development Program G1999012002, and The Cheung Kong Scholars Programme in China.

\section{LITERATURE CITED}

Coles JA, Pipe RK (1994) Phenoloxidase activity in the haemolymph and haemocytes of the marine mussel Mytilus edulis. Fish Shellfish Immunol 4:337-352

Kanchanaphum P, Wongteerasupaya C, Sitidilokratana N, Boonsaeng V, Panyim S, Tassanakajon A, Withyachumnarnkul B, Flegel TW (1998) Experimental transmission of white spot syndrome virus (WSSV) from crabs to shrimp Penaeus monodon. Dis Aquat Org 34:1-7

Kondo M, Itami T, Takahashi Y (1992) The phenoloxidase activity in prawn hemocytes. Fish Pathol 12:185-189

Lightner DV (1999) The penaeid shrimp viruses TSV, IHHNV, WSSV, and YHV: current status in the Americas, available diagnostic methods, and management strategies. J Appl Aquacult 9:27-52

Lo CF, Ho CH, Peng SE, Chen $\mathrm{CH}$ and 7 others (1996) White spot syndrome baculovirus (WSBV) detected in cultured and captured shrimp, crabs and other arthropods. Dis Aquat Org 27:215-225

Lu Y, Tapay LM, Loh PC (1996) Development of a nitrocellulose-enzyme immunoassay for the detection of yellowhead virus from penaeid shrimp. J Fish Dis 19:9-13

Poulos BT, Lightner DV, Trumper B, Bonami JR (1994) Monoclonal antibodies to a penaeid shrimp parvovirus, infectious hypodermal and hematopoietic necrosis virus (IHHNV). J Aquat Anim Health 6:149-154

Xu YW (1997) Immunology diagnostic techniques. Science Press, Beijing, p 181-182

Zhan WB, Wang YH, Fryer JL, Okubo K, Fukuda H, Yu KK, Meng QX (1999) Production of monoclonal antibodies (MAbs) against white spot syndrome virus (WSSV). J Aquat Anim Health 11:17-22

Submitted: February 13, 2002; Accepted: October 31, 2002

Proofs received from author(s): February 7, 2003 